\title{
Os odontoideum in wolcott-rallison syndrome: a case series of 4 patients
}

\author{
R. P. Dias ${ }^{1}$, C. R. Buchanan ${ }^{2}$, N. Thomas ${ }^{3}$, S. Lim ${ }^{4}$, G. Solanki ${ }^{5}$, SEJ Connor ${ }^{6}$, T. G. Barrett ${ }^{1,7}$ and R. R. Kapoor ${ }^{2 *}$
}

\begin{abstract}
Wolcott-Rallison Syndrome is the commonest cause of neonatal diabetes in consanguineous families. It is associated with liver dysfunction, epiphyseal dysplasia, and developmental delay. It is caused by mutations in eukaryotic translation initiation factor 2-a kinase 3 (EIF2AK3).

We report 4 children with WRS and Os Odontoideum resulting in significant neurological compromise. This cervical spine abnormality has not previously been described in this syndrome. This additional evidence broadens the clinical spectrum of this syndrome and confirms the role of EIF2AK3 in skeletal development. Furthermore, Os Odontoideum needs to be actively screened for in WRS patients to prevent neurological and respiratory compromise.
\end{abstract}

Keywords: Neonatal Diabetes, Os Odontoideum, Wolcott-Rallison Syndrome, Atlanto-axial instability

\section{Letter to the editor}

Wolcott-Rallison Syndrome (WRS; OMIM 226980) is a rare autosomal recessive disorder characterised by infancy onset insulin-dependent diabetes and multiple epiphyseal dyspasia [1]. It is caused by mutations in the gene encoding eukaryotic translation initiation factor 2$\alpha$ kinase 3 (EIF2AK3) which is located at Chromosome 2p12 [2]. EIF2AK3 acts as a stress sensor and, upon activation, phosphorylates EIF2alpha and regulates synthesis of unfolded proteins in the endoplasmic reticulum [3]. Other reported clinical features of WRS include recurrent episodes of severe (potentially fatal) hepatic dysfunction, renal impairment and developmental delay [4, 5]. The multiple epiphyseal dysplasia associated with WRS characteristically affects the long bones, pelvis and vertebrae. Osteoporosis has also been described in association with WRS in some patients [6].

We report four patients with WRS and Os odontoideum, a cervical spine abnormality not previously reported in associated with WRS. Os odontoideum is a condition where the odontoid peg is radiologically separated from the body of the second cervical vertebra although continuity with cartilagenous (unossified) tissues has not been clearly defined [7]. Two of the four patients

\footnotetext{
* Correspondence: ritikakapoor@nhs.net

²Department of Child Health, King's College Hospital, London SE5 9RS, UK Full list of author information is available at the end of the article
}

had symptomatic atlanto-axial instability (AAI) requiring spinal fusion to relieve symptoms.

\section{Case reports}

\section{Patient 1}

This female patient, now aged 21 years, presented with antibody negative (Islet Cell / Glutamic Acid decarboxylase) diabetes mellitus aged 6 months. Her parents are White British and unrelated. At 3 years of age, she developed acute liver failure, encephalopathy and renal dysfunction during a minor febrile illness. She recovered completely except for residual cerebellar signs (dysarthria, ataxia). Progressive growth failure developed from 3-4 years of age prompting assessment of pituitary function which did not reveal any abnormality. Hand radiography revealed acro-osteolysis of distal phalanges 1,3 and 5 and the dysplastic carpal bones. Subsequent skeletal survey confirmed multiple epiphyseal dysplasia with hip subluxation and extensive calcification of soft tissues around the knee joints. WRS was confirmed on genetic testing which revealed compound heterozygosity for a frameshift mutation c.577delA and a missense mutation R632W (c.1966C > T) in exons 3 and 12 of the E1F2AK3 gene, (previously reported [8].

Aged 11 years, worsening gait, lower limb pain, reduced mobility and evolution of upper motor neurone long tract signs led to radiological evaluation of cervical 

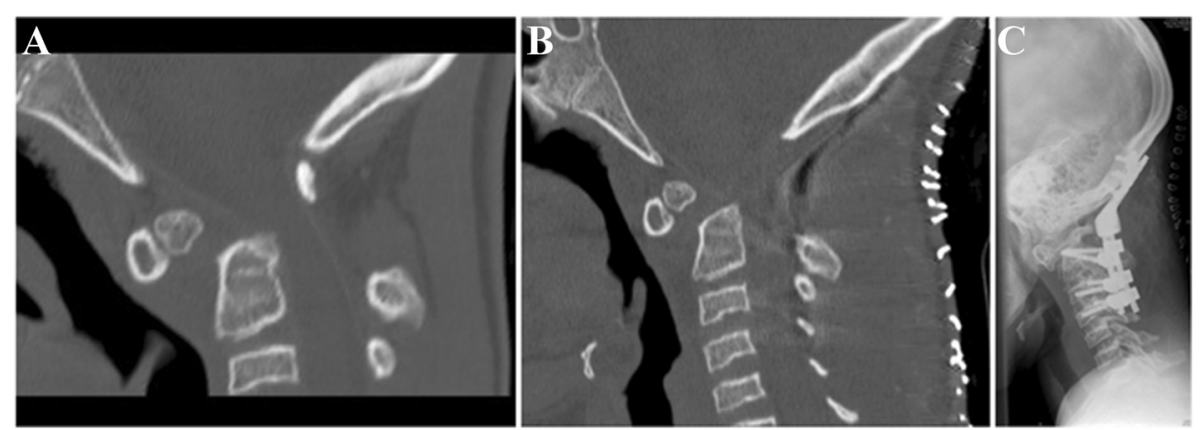

Fig. 1 Radiological images from Case 1. a) Pre-operative sagittal midline CT (on bone windows) shows an os odontoideum widely separated from the body of C2 with a widening of the anterior atlanto-dental distance. There is a marked reduction in the sagittal bony canal dimensions between C2 body and the $C 1$ posterior arch) b) Post-operative sagittal midline $C T$ (on bone windows) demonstrates resection of the posterior arch of atlas and some reduction of the os odontoideum with a reduced distance between the os and the body of C2. c) Lateral plain radiograph demonstrates the occipito-cervical rod and screw fixation

anatomy. Neuroimaging revealed an Os Odontoideum with spinal cord compression (Fig. 1a). Imaging of the neck showed normal position of the $\mathrm{C} 1$ anterior vertebral body and $\mathrm{C} 2$ main body with absence of ossification of the main body of the odontoid peg (Fig. 1a). The odontoid peg tip was normally sited in relation to the $\mathrm{C} 1$ vertebra but had become distracted from the main body of $\mathrm{C} 2$. The posterior body of $\mathrm{C} 1$ was normally positioned and readily visible in the sagittal view (Fig. 1a). The patient underwent successful occipito-cervical fusion to preserve the spinal canal and alleviate bone pressure on the spinal cord (fixation with pedicle screws into $\mathrm{C} 2$ and subaxial lateral mass screws and decompression with removal of the $\mathrm{C} 1$ lamina), (Fig. $1 \mathrm{~b}$ and c). The patient made an uneventful recovery from surgery with improvement of her myelopathic symptoms and signs.

\section{Patient 2}

This male patient presented with diabetes mellitus and concurrent acute hepatic and renal dysfunction at 11 months of age. Detailed clinical and molecular genetic findings confirming the diagnosis of WRS is published elsewhere but he was found to have a homozygous frameshift mutation in exon 9 (c.1635_1638delGAAA) of EIF2KA3 [8]. The diagnosis of Os odontoideum in case 1 prompted imaging in this patient at 9 years of age. The sagittal MRI view confirmed lack of ossification of the odontoid peg (Fig. 2). Imaging did not identify AAI and without clinically apparent neurological consequences of the odontoid abnormality and therefore, a conservative approach to management was adopted. The patient unfortunately died at the age of 12 years from acute liver failure.

\section{Patient 3}

Case 3, aged 14.5 years at the most recent assessment has previously been reported in a case series when
4 years old [9]. He is the youngest of five siblings from consanguineous Pakistani parents. His oldest sister also has WRS and both carry the same homozygous missense mutation in EIF2AK3 (c.1832G > A, R587Q) [2].

He presented aged 10 weeks with an upper respiratory tract infection, vomiting and hyperglycaemia. His diabetes remains poorly controlled with HbA1c persistently greater than $8 \%$. He was noted to have elevated liver enzymes and percutaneous liver biopsy showed progressive

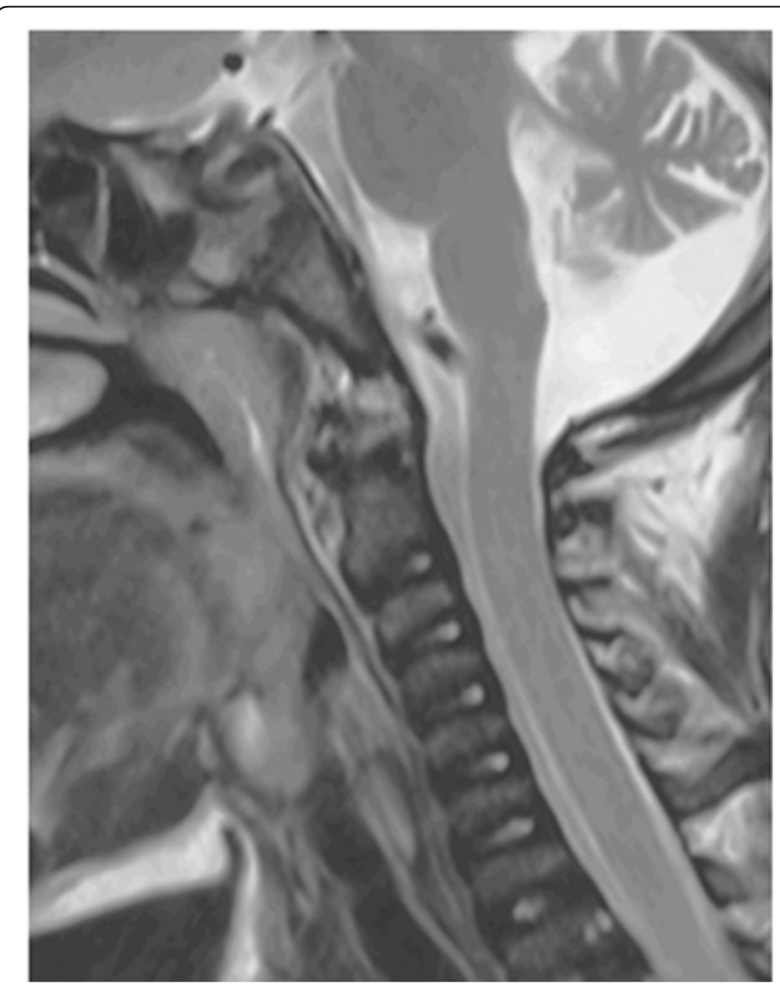

Fig. 2 Radiological image from Case 2. Midline sagittal T2w image demonstrates lack of ossification of the dens 
fibrosing intrahepatic cholestasis. Skeletal radiography revealed dysplastic femoral epiphyses.

At 3.8 years, he presented with encephalitis associated with significant loss of gross and fine motor skills, acute hepatitis and consistent EEG findings. Over the next 4 years his motor development improved, although remained delayed. He became wheelchair bound aged 7 years when imaging identified a $12 \mathrm{~mm}$ anterior translation of $\mathrm{C} 1$ on $\mathrm{C} 2$ flexion (Fig. 3a) He was initially managed conservatively with a cervical hard collar. MRI scan (Fig. 3b) confirmed AAI and over the next 3 years, neuro-surgical opinions repeatedly recommended surgical fixation. The family declined to follow this advice because of concerns regarding surgical risk despite progressive deterioration both on MRI and clinical assessment of upper and lower limb neurological signs, (reduced power and increased tone). Aged 11.9 years, he presented in cardio-respiratory arrest secondary to spinal cord injury. He was resuscitated successfully and underwent surgical $\mathrm{C} 1-\mathrm{C} 2$ posterior fixation (Fig. 3c). Following surgery, he was paraplegic and required longterm home ventilation. He died aged 15 years following an episode of acute liver failure.

\section{Patient 4}

This male patient is now 4 years of age and the younger sibling of case 2 . He had the same homozygous mutation (c.1635_1638delGAAA) of EIF2KA3. He presented aged 4 months of age with abnormal liver enzymes typical of WRS and diabetes. Due to his brother's diagnosis he was tested for WRS and found to have the same mutation. His diabetes is controlled well on continuous subcutaneous insulin infusion. He has had recurrent episodes of acute liver dysfunction. Aged 3.5 years he developed right-sided focal seizures associated with left hemisphere focal epileptiform discharge on EEG and some evidence of cerebral atrophy in the left hemisphere. These are improving on anti-epileptic medication (ethosuximide, levetiracetam and clobazam). Cranioverterbral imaging showed os odontodium to be present, but with no instability on flexion-extension x-rays. Present management is conservative, as with his brother in view of the lack of AAI.

\section{Discussion}

There are fewer than 60 published cases of WRS in the literature event though, it is the most common cause of neonatal diabetes in patients of consanguineous parents [4]. To date, there appears to be no clear genotypephenotype correlation, even within a family as seen with patient 3 whose sibling has neither hepatic dysfunction nor evidence of AAI [5]. Early-onset diabetes, skeletal dysplasia and deranged liver enzymes are the cardinal features of WRS, and all the patients reported here demonstrate these defects. Additional reported features including renal impairment, neutropenia, hypothyroidism and developmental delay are much more variable [10]. Although atlanto-axial instability has previously been reported in this condition, radiological imaging was not shown and os odontoideum was not a reported feature in this single case [11]. Here we report 2 siblings in addition to 2 further unrelated cases, with os odontoideum an upper cervical spine anomaly not previously reported in WRS but of potentially high clinical significance. Os odontoideum is uncommon, characterised by the appearance of a corticated oval or roundshaped ossicle of variable size, representing the odontoid process but with failure to show ossified continuity with the body of the axis [12]. It can lead to AAI and spinal cord compression. Two of the four patients reported here had significant AAI causing neurological changes and required cervical spine fixation. As seen in case 3, the condition has potentially devastating consequences if AAI is left untreated. Although the siblings (Cases 2 and 4) show evidence of the condition occurring as a consistent phenotype with their particular gene mutation, this cannot be extrapolated given the small numbers involved and the lack of $\mathrm{OO}$ in the sibling of Case 3 (not presented here). We have a further 7 patients across the two centres with genetically confirmed WRS. 5 of these

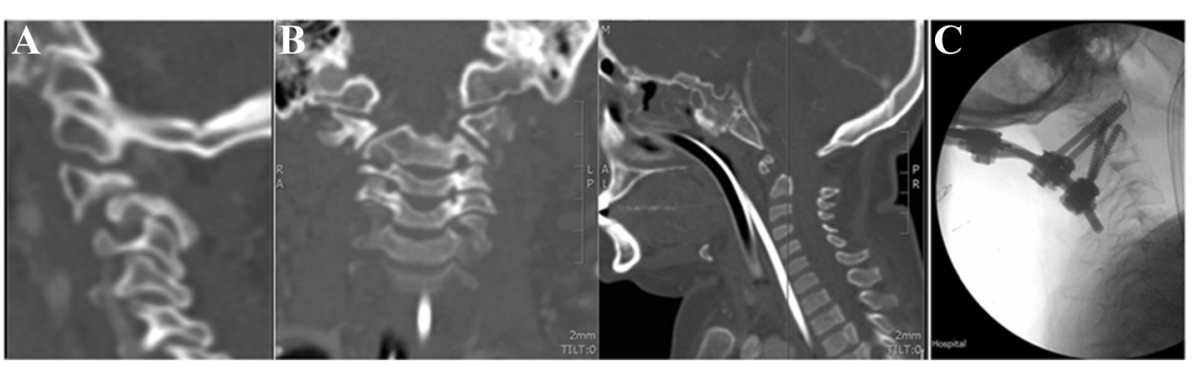

Fig. 3 Radiological images from Case 3. a Pre-operative CT scan showing C1-2 subluxation with antero-inferior subluxation of C1 lateral mass on C2; (b) pre-operative MRI images showing coronal and sagittal views of C2 demonstrating congenital dens hypoplasia with central dip typical of embryological abnormality and absence of posterior arch of C1; (c) post-operative XR image showing occipital C2 fixation following C1-2 reduction (C1 now in line with C2) 
are younger than 5 years of age (age at which ossification is thought to complete) and hence although they have no evidence of neurological deficits or abnormalities on cervical spine X-rays, we cannot exclude later development of OO and/or AAI. A further case was only genetically confirmed post-mortem and so screening had not been undertaken. The final case is the older sister of Case 3 and has no evidence of OO or AAI on screening at present.

The aetiology of Os odontoideum has been attributed to congenital or traumatic mechanisms although current thinking is that the latter is more likely [12]. The presence of this rare anomaly in three unrelated patients with WRS suggests a congenital mechanism in our cases. EIF2AK3 is known to be induced by ER stress caused by malfolded proteins and leads reduction of translational initiation and repression of protein synthesis as well as G1 growth arrest with pleiotropic effects. Although the mechanism by which EIF2AK3 effects abnormal skeletal development and defective bone mineralisation, is as yet unknown, it has a clear role in these processes. This is not only demonstrated by patients with WRS but also in knockout mice who show a number of skeletal defects including deficient mineralization, osteoporosis, and abnormal compact bone development [13]. In addition, researchers have found an association with common variants in EIF2AK3 and reduced bone mineral density (although this is limited data, and only suggestive) [14]. Os odontoideum has also been described in association with other syndromes, with Downs syndrome being the commonest syndrome described previously $[15,16]$. Hajdu-Cheney syndrome is also associated with acroosteolysis of the phalanges and rarely cervical instability, which might suggest a common but as yet unidentified mechanism for the Os odontoideum [17]. However, it has also been suggested that the associated ligamentous laxity and defective ossification in these syndromes predisposes children with these underlying conditions to traumatic Os odontoideum [12]. Similarly, in WRS, it is possible that the underlying bony abnormalities (osteopenia and defective ossification) predispose the development of traumatic Os odontoideum. Multiple fractures frequently observed in WRS favour this hypothesis of a traumatic/acquired lesion in the background of congenital predisposition.

Os odontoideum may be asymptomatic or may cause symptoms due to spinal cord compression or vertebral artery compression [12] and symptoms may be transient [16]. The diagnosis of this anomaly is based on plain radiographs, assisted by computed tomography and magnetic resonance imaging techniques. If Os odontoideum is associated with AAI or neurological deficits, neurosurgical intervention is warranted [12]. Surgical fixation has the potential to prevent devastating consequences although equally carries its own significant risk which families and the medical team may decide is too great to carry out the intervention. We therefore recommend that assessment of children with WRS should include an appropriate and thorough regular neurological assessment, including imaging from diagnosis.

\section{Competing interests}

The authors declare that they have no competing interests.

\section{Authors' contributions}

RPD wrote the manuscript; CRB, SL, TGB and RRK submitted clinical information and were involved editing the manuscript; NT, SEC and GS submitted clinical information and reported on the radiological images. RRK and TGB conceived the article and were responsible for the final version. All authors read and approved the final manuscript.

\section{Acknowledgements}

Genetic analysis was performed by the Molecular Genetics Laboratory at Royal Devon and Exeter NHS Healthcare Trust, UK and was funded by Wellcome Trust.

\section{Author details}

${ }^{1}$ Department of Paediatric Endocrinology and Diabetes, Birmingham Children's Hospital, Birmingham B4 6NH, UK. 'Department of Child Health, King's College Hospital, London SE5 9RS, UK. ${ }^{3}$ Department of Neurosurgery, Kings College Hospital, London SE5 9RS, UK. ${ }^{4}$ Department of Paediatrics, St John's Hospital, Chelmsford, Essex CM2 9BG, USA. ${ }^{5}$ Department of Neurosurgery, Birmingham Children's Hospital, Birmingham B4 6NH, UK.

${ }^{6}$ Department of Neuroradiology, Kings College Hospital, London SE5 9RS, UK. ${ }^{7}$ Centre for Rare Diseases and Personalized Medicine, Institute of Biomedical Research (West), School of Clinical and Experimental Medicine, University of Birmingham, Birmingham B15 2TT, UK.

Received: 22 July 2015 Accepted: 3 February 2016

Published online: 10 February 2016

\section{References}

1. Wolcott CD, Rallison ML. Infancy-onset diabetes mellitus and multiple epiphyseal dysplasia. J Pediatr. 1972;80(2):292-7.

2. Delepine M, Nicolino M, Barrett T, Golamaully M, Lathrop GM, Julier C EIF2AK3, encoding translation initiation factor 2-alpha kinase 3, is mutated in patients with Wolcott-Rallison syndrome. Nat Genet. 2000;25(4):406-9.

3. Shi Y, Vattem KM, Sood R, An J, Liang J, Stramm L, et al. Identification and characterization of pancreatic eukaryotic initiation factor 2 alpha-subunit kinase, PEK, involved in translational control. Mol Cell Biol. 1998:18(12):7499-509.

4. Rubio-Cabezas O, Patch AM, Minton JA, Flanagan SE, Edghill EL, Hussain K, et al. Wolcott-Rallison syndrome is the most common genetic cause of permanent neonatal diabetes in consanguineous families. J Clin Endocrinol Metab. 2009;94(11):4162-70.

5. Ozbek MN, Senee V, Aydemir S, Kotan LD, Mungan NO, Yuksel B, et al. Wolcott-Rallison syndrome due to the same mutation (W522X) in EIF2AK3 in two unrelated families and review of the literature. Pediatr Diabetes. 2010;11(4):279-85

6. Al-Gazali LI, Makia S, Azzam A, Hall CM. Wolcott-Rallison syndrome. Clin Dysmorphol. 1995;4(3):227-33.

7. Matsui H, Imada K, Tsuji H. Radiographic classification of Os odontoideum and its clinical significance. Spine (Phila Pa 1976). 1997;22(15):1706-9.

8. Engelmann G, Meyburg J, Shahbek N, Al-Ali M, Hairetis MH, Baker AJ, et al. Recurrent acute liver failure and mitochondriopathy in a case of WolcottRallison syndrome. J Inherit Metab Dis. 2008;31(4):540-6.

9. lyer S, Korada M, Rainbow L, Kirk J, Brown RM, Shaw N, et al. WolcottRallison syndrome: a clinical and genetic study of three children, novel mutation in EIF2AK3 and a review of the literature. Acta Paediatr. 2004;93(9):1195-201.

10. Julier C, Nicolino M. Wolcott-Rallison syndrome. Orphanet J Rare Dis. 2010;5:29. 
11. Durocher F, Faure R, Labrie Y, Pelletier L, Bouchard I, Laframboise R. A novel mutation in the EIF2AK3 gene with variable expressivity in two patients with Wolcott-Rallison syndrome. Clin Genet. 2006;70(1):34-8.

12. Arvin B, Fournier-Gosselin MP, Fehlings MG. Os odontoideum: etiology and surgical management. Neurosurgery. 2010;66(3 Suppl):22-31.

13. Zhang P, McGrath B, Li S, Frank A, Zambito F, Reinert J, et al. The PERK eukaryotic initiation factor 2 alpha kinase is required for the development of the skeletal system, postnatal growth, and the function and viability of the pancreas. Mol Cell Biol. 2002;22(11):3864-74.

14. Liu J, Hoppman N, O'Connell JR, Wang H, Streeten EA, McLenithan JC, et al. A functional haplotype in EIF2AK3, an ER stress sensor, is associated with lower bone mineral density. J Bone Mineral Res. 2012;27(2):331-41.

15. Hericord O, Bosschaert P, Menten R, Dembour G. Misleading appearance of atlantoaxial diastasis in Down syndrome: os odontoideum. Jbr-Btr. 2009:92(5):261

16. Robson KA. Os odontoideum: rare cervical lesion. West J Emerg Med. 2011:12(4):520-2.

17. Herscovici DBJ. Scott Cl Cervical instability as an unusual manifestation of Hajdu-Cheney syndrome of acroosteolysis. Clin Orthop Relat Res. 1990;255:111-6

Submit your next manuscript to BioMed Central and we will help you at every step:

- We accept pre-submission inquiries

- Our selector tool helps you to find the most relevant journal

- We provide round the clock customer support

- Convenient online submission

- Thorough peer review

- Inclusion in PubMed and all major indexing services

- Maximum visibility for your research

Submit your manuscript at www.biomedcentral.com/submit
Biomed Central 